\title{
The Earth's magnetic field in Italy during the Neolithic period: New data from the Early Neolithic site of Portonovo (Marche, Italy)
}

Earth and Planetary Science Letters, Elsevier, 2016, 448, pp.49 -61.

$\langle 10.1016 /$ j.epsl.2016.05.003
Evdokia Tema ${ }^{a, b,}{ }^{*}$, Enzo Ferrarac ${ }^{c}$, Pierre Camps ${ }^{d}$, Cecilia Conati Barbaro ${ }^{e}$, Simone Spataforac, Claire Carvallof, Thierry Poidras ${ }^{d}$

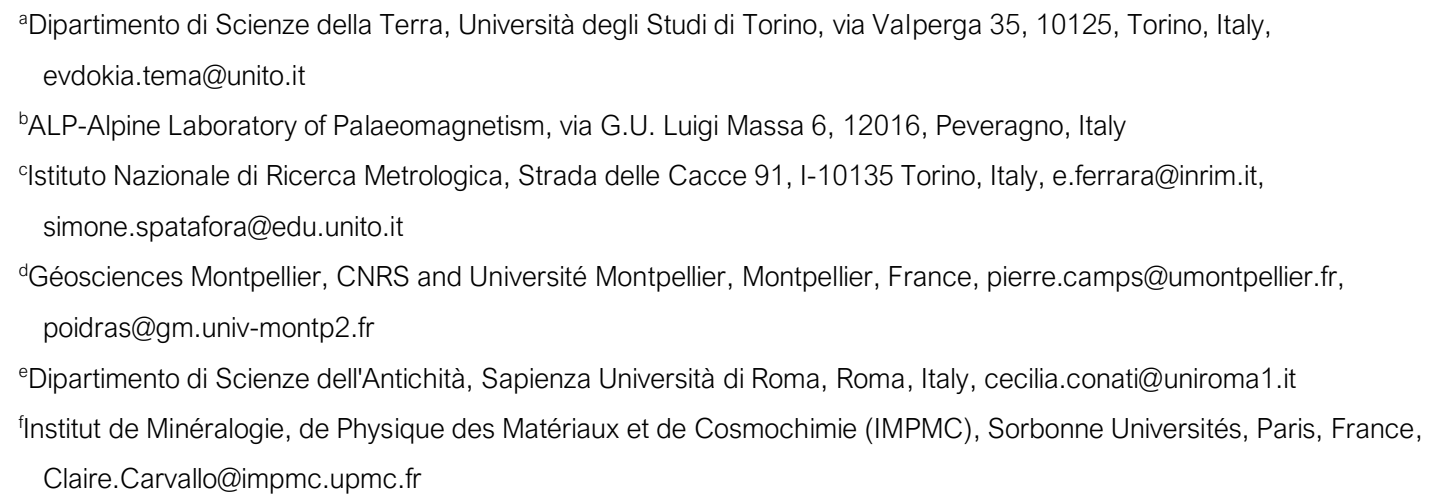

\begin{abstract}
We present new, full geomagnetic field vector results from three Neolithic ovens discovered at the archaeological site of Portonovo (Marche, Italy). The discovered structures are a rare example of very well preserved underground ovens from the Early Neolithic period. Standard thermal demagnetization procedures were used to isolate the direction of the Characteristic Remanent Magnetization acquired by the baked clay during the ovens' last firing. The corresponding archaeointensities were determined by the multi-specimen procedure (MSPDSC) and show a clear intensity low during the Neolithic period. Both directional and intensity results are of high quality, offering the first contribution of full geomagnetic field vector data for this period in Italy. The new data are compared with other contemporaneous data from Europe and with global geomagnetic field models. Independent archaeomagnetic dating of the three ovens was also performed by means of the SCHA.DIF.14k model. The obtained results are in excellent agreement with available radiocarbon dates and confirm that all ovens belong to the Neolithic. These new data importantly enrich our knowledge of the geomagnetic field during the Neolithic period that is poorly documented by data, not only in Italy but also in the whole of Europe and show that archaeomagnetic dating can provide precise results even for prehistoric periods.
\end{abstract}


Keywords: Palaeosecular variation; archaeomagnetism; oven; Neolithic; Italy

\section{Introduction}

Archaeomagnetic data from ancient baked clay archaeological structures is a precious source of information about the past variations of the Earth's magnetic field. Thanks to archaeomagnetic records from well dated archaeological artefacts, it is possible to model the variations of the geomagnetic field in the past and better understand its past behaviour. Up to now, local Secular Variation (SV) curves have been established for several countries, mainly in Europe, and different geomagnetic field models have been proposed based on the available archaeomagnetic data at regional and global level. However, most of the proposed SV curves cover only the last three millennia, while the geomagnetic field variations in earlier times are still poorly described.

In Italy, Tema et al. (2006) have published a preliminary SV curve based on 65 directional results ranging in time from 1300 BC to 1700AD. More recently, Tema (2011) compiled an updated dataset of Italian archaeomagnetic data, presenting 73 directional and 23 intensity determinations. From these data, only six directional results come from material older than 1000 BC. This significant lack of data from periods previous to the first millennium BC can be attributed to several factors, including the very limited number of well preserved still in situ baked clay structures (often due to the use of poor building materials in prehistoric times) and the difficulty of precise independent dating of such old and badly preserved structures.

In this study, we present new, full geomagnetic field archaeomagnetic results from three Neolithic ovens excavated at the archaeological site of Portonovo (Marche, Italy). The discovered ovens are a rare example of very well preserved underground ovens and have the advantage of being from a well dated archaeological context with three radiocarbon dates. The new results are the first full geomagnetic field vector data available for this period in Italy and importantly enrich our knowledge about the geomagnetic field during the Neolithic period.

\section{Archaeological site and sampling}

The archaeological site of Portonovo Fosso Fontanaccia $\left(43.56^{\circ} \mathrm{N}, 13.57^{\circ} \mathrm{E}\right)$, is situated on the Conero promontory, along the Adriatic coast of Marche (Ancona, Italy). It is located on a south-facing slope, along the right bank of the river Fontanaccia. It was first identified in the 1990s; since then, several excavation campaigns brought into light a total of 22 domed ovens, at different heights along the hillside (Fig. 1). The ovens were built by digging small cavities into the colluvial layer. Almost all of them overlook large depressions in front of their openings. Six of the ovens were found totally intact (Conati Barbaro, 2013). Despite their different states of preservation, all ovens share similar features and dimensions: the base is circular, flat, with a 
slight central depression, made of yellow-reddish smoothed clay lining, and measuring from 1.8 to 2.0 meters in diameter; the vaults are very low, so that the maximum height in the six ovens found intact does not exceed $50 \mathrm{~cm}$; the mouths are between 60 and $80 \mathrm{~cm}$ in width. The inner surfaces were partially coated with clay and subsequently consolidated by the firing.

Information about the maximum firing temperatures reached during the use of the Portonovo ovens was provided by X-ray powder diffraction analysis (PXRD), based on the transformation of $\mathrm{CaO}$-rich sediments, structurally modified by exposure to low or high temperatures clay (Muntoni and Ruggiero, 2013). PXRD analysis performed on 12 samples from the hardened baked clay of the ovens inner walls revealed the predominance of calcite, a variable amount of quartz and a small quantity of feldspars in all samples. It also revealed the absence of Ca-silicates newly formed by exposure to high temperatures, such as diopsidic pyroxenes or gehlenite, typical of CaO-rich clay (Muntoni and Ruggiero, 2013). These results suggest that the sediments were heated at temperatures not higher than $500{ }^{\circ} \mathrm{C}$ (Muntoni and Ruggiero, 2013). Based on these relative low heating conditions, the use of the ovens for pottery production may be excluded, as in that case higher heating temperatures would be expected. The presence of charred cereal grains, mainly barley, within ovens 14,15 and 16, leads to the hypothesis that they were used for food processing and cooking, as well as for other purposes, such as heating flint. In fact, many blades and bladelets found inside and outside the ovens show clear signs of thermal treatment (Conati Barbaro, 2013). Moreover, two ovens contained three adult burials (two in oven 1 and one in oven 5). The secondary use of domestic structures as sepultures, which is quite a common funerary practice during the Neolithic, probably occurred when the structure itself, or perhaps the entire area, lost their primary function.

According to the archaeological evidence, the ovens were used in the same time period but most likely not all of them at the same moment. Each oven was probably constructed, used for few years and then abandoned, as there is no evidence of maintenance to extend its functional life. After abandonment of one oven, another one was made just next to the damaged one. Based on the decoration style of some pottery found, the site could be linked to the middleAdriatic facies of the Italian ancient Neolithic (Conati Barbaro, 2013). The homogeneity of the materials and the stratigraphic data also indicate that the site was occupied for a short period of time. Dating obtained from radiocarbon analysis also supports this hypothesis. Three radiocarbon dates have been obtained so far (Conati Barbaro, 2013), all of them carried out at CEDAD (Centro di Datazione e Diagnostica) of the University of Salento, Italy, using the Accelerator Mass Spectrometry (AMS) technique. Radiocarbon results were calibrated using the OxCal 3.1 software after comparison with the atmospheric data reference curves (Reimer at al., 2004; 2009) and calibrated ages were calculated at $95 \%$ of probability. The oldest date, carried out on a barley caryopsis found inside the oven 14, suggests a calibrated age 5620-5460 BC (6555 \pm 45 BP, Lab code: LTL12777A). The other two dates come from findings inside the oven 5; one from charcoal collected from the floor of the oven dated at 5560-5350 BC $(6500 \pm 50 \mathrm{BP}$, Lab 
code: LTL5192A), and the other from a bone of the male burial dated at 5480-5310 BC (6418 \pm 50 BP, Lab code: LTL5191A). Even though it is not possible, based on the archaeological evidence and the $\mathrm{C} 14$ results, to precisely date the time of use and abandonment of each oven, it is however certain that all of them belong to the Early Neolithic period and they have been used between 5620-5310 BC.

For the archaeomagnetic study presented here, baked clay samples from the ovens 14 (PFO-14), 16 (PFO-16) and 17 (PFO-17) have been collected (Fig. 1). These ovens were excavated in 2013 and archaeomagnetic sampling was carried out in October 2013. All of the studied ovens were found intact, with their walls and vaults almost entirely preserved. Ovens PFO-14 and PFO-16 overlooked a large shallow pit. Unlike these, oven PFO-17 has a trapezoidal shape and was originally excavated on the edge of another pit. Ovens PFO-14 and PFO-16 were filled with organic sediment containing dozens of charred cereal grains. Archaeological findings, such as pottery and lithics, were rare within all the studied structures.

Initially, archaeomagnetic sampling was attempted using a portable rock drill. However, even though the baked clay that constituted the floor and the walls of the ovens was apparently compact, it proved to be extremely friable when drilled. Most of the drilled cores broke in small pieces when extracting them from the oven and thus they were only used for magnetic mineralogy analysis and archaeointensity determinations. Systematic sampling was therefore performed with non-magnetic cylindrical plastic boxes of standard dimensions (diameter= 25 $\mathrm{mm}$, height $=20 \mathrm{~mm}$ ). A total of 38 samples were collected from the floor of the three ovens (15 samples from oven PFO-14, 11 from oven PFO-16 and 12 from oven PFO-17). All of them were independently oriented in situ with a magnetic compass and an inclinometer.

\section{Rock magnetic experiments}

Detailed magnetic mineralogy experiments on representative samples from the three ovens have been performed in order to better understand the nature, the type, the size and the thermal stability of magnetic minerals included in the collected baked clays.

\subsection{Viscosity index}

In order to investigate the stability of the magnetization carried by the studied samples, the viscosity index v (\%) (Thellier and Thellier, 1944; Prévot, 1981) has been calculated for the whole sample collection. The remanent magnetization was first measured after a 15 days storage of the samples with their positive cylindrical axis oriented parallel to the laboratory ambient field. Next, the remanent magnetization was measured again after subsequent 15 days storage in zero field (shielded chamber). The viscosity index was then calculated as the vector difference between the two measurements. It was used as a quantitative estimate of the ratio of the Viscous Remanent Magnetization (VRM) acquired in situ until the sampling, to the primary remanent 
magnetization acquired during the last use of the ovens. For the majority of the samples, the viscosity index varies from $5 \%$ to $15 \%$ and only for four samples from PFO-14 oven it is as high as $20 \%$ (Fig. 2a). In order to guarantee that a possible VRM does not importantly affect our results, we have further stored all samples in zero field for 30 days before beginning the measurements.

\subsection{Isothermal remanent magnetization curves}

Isothermal remanent magnetization (IRM) curves have been obtained for nine samples (three from each oven) at the ALP Palaeomagnetic laboratory (Peveragno, Italy). An ASC pulse magnetizer was used to impart the IRM, applying stepwise increasing magnetic fields up to 1.6 T, and the remanent magnetization was measured with a JR6 spinner magnetometer (AGICO). The normalized IRM acquisition curves obtained from the different samples are very similar and show that in most cases saturation is reached at applied fields of 0.2-0.4 T (Fig. 2b). These results suggest the presence of a low coercivity mineral as the main carrier of magnetization, most probably magnetite.

\subsection{Thermal demagnetization of a three-axes IRM}

An IRM was imparted with an ASC pulse magnetizer along three orthogonal axes of representative samples, applying first a maximum $1.6 \mathrm{~T}$, then a medium $0.5 \mathrm{~T}$ and finally a minimum 0.1 T magnetic field. Stepwise thermal demagnetization of this composite IRM was performed to obtain unblocking temperatures of hard-, medium- and soft-magnetic components (Lowrie, 1990). The demagnetization curves obtained show that in all samples, most of the magnetization is carried by the magnetically soft fraction $(<0.1 \mathrm{~T})$ while the medium and highcoercivity components are generally very small (Fig. 2c). All samples are completely demagnetized at temperatures around $540-560{ }^{\circ} \mathrm{C}$ while in some cases a drop of magnetization is noticed at temperatures around $280^{\circ} \mathrm{C}$. These data confirm the dominance of a low coercivity mineral, most probably magnetite, while some magnetic phase with low Curie temperature may be also present.

\subsection{Magnetic susceptibility versus temperature $(k-T)$ curves}

Low-field magnetic susceptibility versus temperature experiments ( $k-T$ curves) are useful to determine the Curie temperature $\left(T_{c}\right)$ and evaluate the stability of the magnetic carriers upon heating. Thermomagnetic k-T curves have been performed at the University of Montpellier, France. First, a piece of baked clay was crushed in an agate mortar and sieved to collect the 0.4$0.8 \mathrm{~mm}$ size fraction. Then $\mathrm{k}-\mathrm{T}$ curves were acquired at low-temperature by means of a cryostat apparatus (CS-L) and at high-temperature under Argon by means of a furnace (CS-3) coupled to the KLY-3 Kappabridge instrument (AGICO, Czech Republic). The studied material was first 
heated from the liquid nitrogen temperature $\left(-194{ }^{\circ} \mathrm{C}\right)$ to about $650^{\circ} \mathrm{C}$ and cooled down to room temperature. The data were corrected for the empty holder and normalized to the maximum susceptibility. The heating-cooling curves obtained are generally reversible, indicating only minor magnetic mineralogical transformations during heating (Fig. 3). The Curie temperature is estimated to be around $580^{\circ} \mathrm{C}$ suggesting the presence of magnetite, which is in agreement with our previous experiments. Furthermore, these results show that the studied material is thermally stable and suitable for archaeointensity study.

\subsection{Hysteresis curves}

Hysteresis loops and magnetic moment versus temperature profiles from representative samples were measured at INRIM (Torino, Italy) with a Lake Shore 7400 Vibrating Sample Magnetometer (VSM) equipped with a thermo-resistance oven operating in Ar atmosphere. The parameters obtained from the hysteresis curves are plotted in a Day plot (Day et al., 1977) in order to investigate the domain state of the magnetic grains (Fig. 4a). All of the studied samples fall in the pseudo single domain range, indicating the presence of a mixture of SD and MD or SD and SP grains (Dunlop and Carter-Stiglitz, 2006). Further investigation of the grain size was following performed with FORC diagrams.

Thermomagnetic curves of saturation magnetization Ms versus temperature (Ms-T) we also performed for representative samples. Small sample chips of around $50 \mathrm{mg}$ were prepared, and for the same sample $\mathrm{Ms}-\mathrm{T}$ curves were repeated at increasing maximum temperatures. Each sample was gradually heated at $430^{\circ} \mathrm{C}$ and cooled back to room temperature by thermal inertia, while its magnetization was continuously measured during both heating and cooling. Then, for the same sample, the heating-cooling circle was repeated up to $540{ }^{\circ} \mathrm{C}$, and finally up to $650{ }^{\circ} \mathrm{C}$ (Fig. 4b). Hysteresis loops have also been measured before and after thermal treatments applying a maximum intensity field, $H_{\max }$, equal to $1 \mathrm{~T}$ (Fig. 4c).

The thermomagnetic curves obtained can offer information about the magnetic mineralogy, thermal stability and grain size of the magnetic carriers but also give evidence about the firing temperatures achieved within the ovens during their use in ancient times. Indeed, reversible changes of magnetic properties should be expected when samples are experimentally heated at temperatures lower (or equal) to those experienced in the past, e.g. during their use at Neolithic times (Hrouda et al., 2003; Carrancho and Villalain, 2011; Spassov and Hus, 2006) while significant differences are expected at higher temperatures. The results obtained show the prevalence of a soft magnetic phase, with Curie $\left(\mathrm{T}_{\mathrm{c}}\right)$ temperature below $580^{\circ} \mathrm{C}$ (Fig. $\left.4 \mathrm{~b}\right)$, in good agreement with the results obtained from the IRM, Lowrie experiments and $\mathrm{k}$-T curves. Using the derivative function of heating curves during thermomagnetic analysis, $T_{c}$ values have been identified between $573{ }^{\circ} \mathrm{C}$ and $577{ }^{\circ} \mathrm{C}$, with an average temperature corresponding to $575 \pm 2$ ${ }^{\circ} \mathrm{C}$, i.e. near to the Curie point of magnetite. A further confirmation of the dominance of a soft 
magnetic phase is given by the hysteresis loops that show that the magnetization is almost completely saturated at fields of around $0.3 \mathrm{~T}$ (Fig. 4c).

Comparison of the thermomagnetic curves obtained at different temperatures shows that the studied material has an almost reversible behavior up to $430{ }^{\circ} \mathrm{C}$. However, when the sample is heated at higher temperatures (e.g. $540{ }^{\circ} \mathrm{C}$ and $650{ }^{\circ} \mathrm{C}$ ), the heating and cooling curves show an irreversible behavior, indicating that probably mineralogical changes took place during heating (Fig. 4b, c). This is also confirmed by the hysteresis curves that show a clear increase of the coercive force after heating at $650{ }^{\circ} \mathrm{C}$ compared with the coercive force obtained before heating (Fig. 4c). Such increase is probably caused by mineralogical transformations that have produced a higher coercivity mineral, most probably hematite. The results obtained here suggest that the firing temperatures of the ovens in ancient times were between $430{ }^{\circ} \mathrm{C}$ and 540 ${ }^{\circ} \mathrm{C}$, in good agreement with the temperatures estimated by the $\mathrm{X}$-ray powder diffraction analysis (Muntoni and Ruggiero, 2013).

\subsection{First order reversal curves (FORC diagrams)}

In order to further characterize the grain size of the samples, first-order reversal curve (FORC) diagrams were measured with a magnetometer ( $\mu$-VSM) from Princeton Measurements Corporation at the IPGP-IMPMC Mineral Magnetism Analytical Facility. FORC diagrams were measured with an averaging time of $0.1 \mathrm{~s}$ and a saturating field of $1 \mathrm{~T}$. One hundred and fifty FORCs were used to calculate each FORC diagram. They were analyzed with the VARIFORC software (Egli, 2013), using a variable smoothing factor. The variable smoothing considerably reduces the noise levels by applying larger smoothing factors to the background, while preserving the areas along the axes with relatively small smoothing factors.

A total of 7 samples from the three ovens were analyzed. The two studied samples from oven PFO-14 show behavior characteristic of stable single-domain grains, with most of the contours closed, and moderate interactions (Fig. 5a) (Roberts et al., 2000). The outermost contours diverge slightly, which could indicate the presence of a small fraction of superparamagnetic (thermally unstable) grains. The coercivity peak is around $20 \mathrm{mT}$ and contours extend as far as 60-70 mT. The two samples from oven PFO-16 are characterized by a peak close to the $\mathrm{Hc}=0$ axis and very little spreading (Fig. $5 b$ ), which seems to indicate the presence of single domain grains, among which some have a relaxation time close to the time of the experiment. Three samples from PFO-17 oven were measured, showing two types of behavior. Sample PFO-17-1 has a FORC diagram very similar to that of PFO-16 (Fig. 5c). The other two samples are characterized by two peaks: one close to the $\mathrm{Hc}=0$ axis and one further away on the $\mathrm{Hc}$ axis, centered at $\mathrm{Hc}=13 \mathrm{mT}$ (Fig. $5 \mathrm{~d}$ ), which indicates the presence of stable and viscous single domain grains. The three types of FORC diagrams suggest the presence of very fine grains and little interactions, making these samples ideal candidates for archaeomagnetic analyses. 


\section{Methods and results}

\subsection{Magnetic anisotropy}

Before the application of the magnetic cleaning, the bulk magnetic susceptibility was measured for all samples. Then, the anisotropy of the magnetic susceptibility (AMS) was investigated in order to examine any possible deviation of the direction of the characteristic remanent magnetization (ChRM) carried by the samples with respect to the direction of the geomagnetic field in the past. All measurements were performed at the ALP palaeomagnetic laboratory with a KLY-3 Kappabridge (AGICO). The low field bulk magnetic susceptibility varies from $1.68 \times 10^{-3}$ to $14.96 \times 10^{-3} \mathrm{SI}$, with the higher values coming from oven PFO-17 (Table 1). The degree of AMS (Pams) (Jelinek, 1981) is very low and varies between $1.002<\mathrm{P}_{\text {AMS }}<1.023$ with mean value 1.008 for oven PFO-14, 1.007 for PFO-16 and 1.005 for PFO-17 (Table 1). The anisotropy results obtained here are in agreement with those from previous studies on prehistoric baked clays (e.g. Kovacheva et al., 2009) and confirm that the anisotropy of baked clays from ovens and fire places is negligible, in contrary to the results from brick kilns or ceramics that are usually highly anisotropic (Chauvin et al., 2000; Hus et al., 2002; Tema, 2009).

\subsection{Archaeomagnetic direction determination}

The natural remanent magnetization (NRM) of 39 samples was first measured with a JR6 spinner magnetometer at the ALP palaeomagnetic laboratory (Peveragno, Italy). Subsequently, all samples were demagnetized applying stepwise alternating field (AF) up to $80 \mathrm{mT}$ with a ASCD 2000 equipment. The plastic boxes used for sampling prevented the application of systematic thermal demagnetization procedures. Almost all samples are demagnetized in relatively low AF fields, around 40-60 mT, confirming the presence of a low coercivity magnetic mineral. Demagnetization results are illustrated in orthogonal vector components diagrams (Zijderveld, $1967)$ and the characteristic remanent magnetization (ChRM) for each sample has been easily isolated (Fig. 6a).

We determined the ChRM by means of principal component analysis (Kirschvink, 1980), averaged the directions thus obtained by oven, and calculated the statistical parameters assuming a Fisherian Distribution (Fisher, 1953). All directions at sample level are reported in Table 1, together with the Maximum Angular Deviation values (MAD). The directions obtained from the three ovens are very similar with each other: $D=357.0^{\circ}, I=60.9^{\circ}, \alpha_{95}=2.0, k=448$ for oven PFO-14, $D=357.0^{\circ}, \mathrm{I}=57.7^{\circ}, \alpha_{95}=2.4, \mathrm{k}=450$ for oven PFO-16 and $\mathrm{D}=352.8^{\circ}, \mathrm{I}=57.9^{\circ}, \alpha_{95}=$ 2.1, $\mathrm{k}=611$ for oven PFO-17 (Fig. $6 \mathrm{~b}$ and Table 1). All mean directions are characterized by small $\alpha_{95}$ angles of confidence and high values of precision parameter $k$. 


\subsection{Archaeomagnetic intensity determination}

Absolute intensity determinations of a collection of samples from the three ovens were carried out at the University of Montpellier with the multispecimen protocol. The multispecimen technique offers a viable alternative to the classical Thellier-Thellier method of absolute palaeointensity determination, having a great potential to improve and simplify the palaeointensity measurements (Dekkers and Böhnel, 2006; Fabian and Leonhardt, 2010). The experiments were performed with a prototype of a very fast-heating infrared furnace developed in Montpellier (FURéMAG, patent \#1256194) which has the advantage of heating small samples of 10-ccstandard volume very quickly and uniformly. A total of 21 samples, 7 from each oven, have been studied with the MSP-DSC protocol (Fabian and Leonhardt 2010). Thanks to the prototype FURéMAG furnace, a precise magnetic induction field, perfectly controlled in 3D with a measured precision better than $1^{\circ}$ was applied to each sample during the heating (and cooling). The heating temperature for the partial thermal remanent magnetization (pTRM) acquisition was chosen to be $320{ }^{\circ} \mathrm{C}$ for all samples; this temperature is considered high enough to involve a sufficient fraction of the TRM (at least $20 \%$ ) but sufficiently low to avoid chemical alteration. In the MSP protocol, the PTRM is imparted along the NRM direction, thus no anisotropy correction is necessary. Moreover, the AMS results previously discussed showed that the Portonovo samples are characterized by a very weak anisotropy that would not effect the applied laboratory field direction. In multispecimen protocol, cooling rate correction is also not required (Fanjat, 2012)

A set of strict criteria was adopted to select the individual MSP data and screen out those of poor technical quality. The applied criteria are essentially based on three considerations.

1. The fraction of unblocked NRM during the heatings must be between $20 \%$ and $80 \%$ of the total NRM. In this interval, the fraction is large enough to be accurately measured and well below a total TRM.

2. The maximum angle between the NRM left after the pTRM acquisition and the total NRM is fixed at $10^{\circ}$.

3. The relative alteration error calt (see equation 19 in Fabian and Leonhardt, 2010) must be lower than $10 \%$.

For the three ovens, all the rejected samples were discarded from further analysis due to a significant alteration error (greater than 10\%). The regression analysis remains possible for oven PFO-14 and for oven PFO-16, with 4 samples selected, while it is unfortunately precluded for oven PFO-17 since only 3 samples were selected. The intensity values obtained for ovens PFO-14 and PFO-16 are very similar, whatever the protocol involved (DB, FC, or DSC) in the archaeointensity determination (for details about the various protocols, see Fabian and Leonhardt, 2010) and whatever the value of alpha parameter (see Table 2 and Figure 7). As recommended by Fabian and Leonhardt (2010) our preferred archaeointensity estimations are those given by the MSP-DSC protocol with the alpha parameter equal to 0.5 , and they are $28.2 \pm$ 
$1.0 \mu \mathrm{T}$ and $26.7 \pm 0.9 \mu \mathrm{T}$ for ovens PFO-14 and PFO-16, respectively. These results show very similar intensities for the two ovens suggesting that they were used and abandoned in short time periods one after the other.

\section{New data and the geomagnetic field in southern Europe during the Neolithic period}

The new archaeomagnetic data presented in this study are the first full geomagnetic field results available up to now in Italy for the Neolithic period. Tema et al. (2006) presented two directional data from baked clay hearths excavated at the Mesolithic site of Laghetti del Crestoso (Brescia, northern Italy). Nevertheless, these results were obtained based only on NRM measurements and zero field viscosity tests and they are characterized by large $\alpha_{95}$ confidence angles ( $\alpha_{95}=11.6^{\circ}$ and $17.7^{\circ}$ respectively). Even though they give some indication about the Earth's magnetic field direction in Italy during the prehistoric time, they cannot be considered reliable enough for secular variation reconstructions. More recently, Kapper et al. (2014) studied different levels of anthropogenic burnt sediments in the Riparo Gaban rock shelter (Trento, northern Italy) and obtained seven new directional results for the time period spanning from 5000 $\mathrm{BC}$ to $2300 \mathrm{BC}$. These results are also characterized by relatively large $\alpha_{95}$ angles, varying from $5^{\circ}$ to $13.3^{\circ}$, probably because of the low combustion temperatures of the sediments and possible disturbances caused by bioturbation and anthropogenic factors (Kapper et al., 2014). No intensity data from Italian artifacts with ages older than the last two millennia are available before now (Tema, 2011).

Archaeomagnetic data from the prehistoric period are also extremely scarce in the whole of central Europe. To our knowledge, only two directional data from Germany and few data from Hungary are available for the 6000-4000 BC period. Schnepp et al. (2004) presented the archaeomagnetic direction of an oven excavated at Untergaiching (southern Germany) and Schnepp and Lanos (2005) obtained one more directional result from Germany by studying the archaeomagnetic direction of an oven excavated at Bernstorf, close to Kranzberg in southern Germany, with an age between 5526 BC and 5373 BC. Márton (2009) published a set of prehistoric archaeomagnetic directions from different sites in Hungary, with ${ }^{14} \mathrm{C}$ ages ranging from $5500 \mathrm{BC}$ to $4490 \mathrm{BC}$ (no age errors are reported in the publication). Regarding the archaeomagnetic intensity data, again almost no data are available, with the exception of few archaeointensity records from Czech Republic reported in the early work of Bucha (1967). Conversely, an extended dataset of both directional and intensity data is available for Eastern Europe, mainly coming from the Balkan Peninsula (Tema and Kondopoulou, 2011). Bulgaria has one of the richest archaeomagnetic records in Europe that covers almost continuously the last 8000 years (Kovacheva et al., 2009; 2014) while an important number of directional (De Marco et al., 2014) and intensity data (De Marco et al., 2008) are also available for Greece. Few data 
from prehistoric times are also available from other countries of Eastern Europe such as Serbia and Romania (Brown et al., 2015, Geomagia50.v3.1 database).

The new full geomagnetic field results presented here are compared with published data from Italy, central Europe and Balkan Peninsula available for the 6000-4000 BC period (Fig. 8). Data from the Balkan Peninsula (Tema and Kondopoulou, 2011) have been updated with some recently published data from Bulgaria (Kovacheva et al., 2014) and Greece (Fanjat et al., 2013), taken from the updated Geomagia50.v3.1 database. For comparison, all data have been relocated at Viterbo $\left(42.45{ }^{\circ} \mathrm{N}, 12.03{ }^{\circ} \mathrm{E}\right)$, situated in central Italy (around $70 \mathrm{~km}$ from Rome), which was chosen as the optimum reference point for archaeomagnetic studies in Italy (Lanza and Zanella, 2003; Tema et al., 2006; 2010). The comparison shows that the directions obtained from the Portonovo ovens are in very good agreement with the data from Germany and Hungary from the same time period (Fig. 8a, b). Good agreement can also be observed with the directional data from the Balkan Peninsula. As far as the intensity data are concerned, Portonovo results clearly show a low intensity value around $28 \pm 1 \mu \mathrm{T}$. This low intensity seems to be confirmed by some data from Bulgaria that show intensity values of around 30-35 $\mu \mathrm{T}$, even though some dispersion in the published data can be noticed around 5500 BC, with intensities as high as $45 \mu \mathrm{T}$ (Fig. 8c).

The new data have been also compared with the predictions of the CALS10k.1b (Korte et al., 2011), the pfm9k.1a (Nilson et al., 2014) and the SCHA.DIF.14k (Pavon-Carrasco et al., 2014) global geomagnetic field models that are the most recently published models that cover the Neolithic period. The Portonovo directions are in very good agreement with the models, while the Portonovo intensity is lower than the models predictions (Fig. 8). Actually, both pfm9k.1a and SCHA.DIF.14k models tend to show an important decrease in intensity for the period around 5500 BC. However, the model predictions show much smoother variations with respect to those indicated by the archaeomagnetic data, probably influenced by the sedimentary records included in the reference dataset of some models for the BC periods and/or the often the important dispersion of the reference data. This clearly highlights the importance of new, high quality data that can contribute to improvement of the models' resolution.

\section{Discussion and conclusions}

The material collected from the Neolithic ovens of Portonovo, even if very fragile and baked at relatively low temperatures $\left(<500{ }^{\circ} \mathrm{C}\right)$, has been shown to be a reliable recorder of the Earth's magnetic field in the past. Both directional and intensity results obtained are of high quality, offering the first full geomagnetic field vector data for Neolithic period in Italy. The directions and intensities recorded by the three ovens are very similar, suggesting that the ovens were in use and abandoned almost at the same time or in time periods very close one to the other, when the geomagnetic field was almost the same. This is in very good agreement with the 
archaeological findings suggesting that each oven was in use for a very short period of time (few years or decades), while the whole site was occupied for just few centuries.

Taking into account the very well determined geomagnetic field vector, with directions accompanied by low $\alpha_{95}$ angles of confidence and intensities characterized by small confidence intervals, we have tried to further investigate the possibility of reconstructing the chronological sequence of the construction and abandonment of the three studied ovens by archaeomagnetic dating. We have therefore compared the declination, inclination and intensity determined for each oven with the predictions of the SCHA.DIF.14k European geomagnetic field model (PavónCarrasco et al., 2014), that is only based on archaeomagnetic and volcanic rock data and therefore offers one of the most reliable global geomagnetic field models for the prehistoric period. For oven PFO-17, dating was performed based only on declination and inclination. Such comparison shows that at $95 \%$ of probability the last firing of each oven occurred at: 5479-5403 BC for oven PFO-14 (or 5463-5429 BC at 65\% of probability), 5472-5395 BC for oven PFO-16 (or 5455-5423 BC at $65 \%$ of probability) and 5522-5359 BC for oven PFO-17 (or 5503-5405 $\mathrm{BC}$ at $65 \%$ of probability). Dating obtained for oven PFO-17 based only on the direction shows a quite wide time interval, demonstrating that the contribution of archaeointensity is very important for restricting the archaeomagnetic dating results. Nevertheless, the dating results of all ovens are in very good agreement with the dating of the site based on archaeological evidence and available ${ }^{14} \mathrm{C}$ dating.

Archaeomagnetic dating results suggest that the PFO-17 oven is most likely to belong to a separate group of ovens and it was damaged and abandoned before ovens PFO-14 and PFO16. On the other hand, ovens PFO-14 and PFO-16 are most probably abandoned at the same time or with very short time difference in presence of actually almost the same ambient geomagnetic field. This hypothesis seems to be also supported by the vicinity of the two ovens, and probably when one was damaged by repeated use, the other was built just attached to the previous one. Of course this interpretation should be used with caution and integrated with other archaeological evidence, as the wide dating interval obtained for oven PFO-17 and the overlapping of the obtained archaeomagnetic dating for PFO-14 and PFO-16 ovens caused by their statistically similar directions and intensities, does not allow more precise chronological reconstruction. Moreover, archaeomagnetic dating always refers to the last firing of the ovens, usually corresponding to their abandonment but it can not offer information about the date of construction or period of use of the structures that could have occurred much earlier.

The new full geomagnetic field vector results presented here aim to offer new data about the Earth's magnetic field in Italy during the Neolithic period and enrich the available global dataset that is still poor for the prehistoric period. The clear, well defined, low intensity values obtained here suggest that the intensity of the Earth's magnetic field around $5500 \mathrm{BC}$ was almost $20 \mu \mathrm{T}$ lower that the today's field in Italy. Such low intensity seems to be an interesting feature of the field in Neolithic period, noticed also in the Balkan Peninsula, and it should be further 
investigated by obtaining new high quality data from Europe from the same chronological period. Undoubtedly, obtaining new data from well-dated archaeological material is also a key issue for improving the resolution of geomagnetic field models in the past, in order to identify the fine features and rapid geomagnetic field variations, as well as extending reliable archaeomagnetic dating in prehistoric periods.

\section{Acknowledgments}

This study was partially financed by the PHC Galileo 2012-2013 exchange program. The Géosciences Montpellier was supported by a grant from the CNRS-PNP. The FUReMAG rapid furnace construction was supported by the French National Agency for Research (ANR-12BS06-0015). Cathy Batt is highly acknowledged for improving the English style and Giorgio Bertotti is sincerely thanked for discussion and suggestions on the manuscript. Elisabeth Schnepp and an anonymous reviewer are acknowledged for their comments on the manuscript. 


\section{References}

Brown, M.C., Donadini, F., Korte, M., Nilsson, A., Korhonen, K., Lodge, A., Lengyel, S.N., Constable, C.G., 2015. GEOMAGIA50.v3: 1. General structure and modifications to the archeological and volcanic database. Earth Planets Space, 67:83, doi:10.1186/s40623-015-0232-0.

Bucha, V., 1967. Intensity of the Earth magnetic field during archeological times in Czechoslovachia. Archaeometry, 10, 12-22, doi: 0.1111/j.1475-4754.1967.tb00608.x.

Carrancho, A., Villalaín, J.J., 2011. Different mechanisms of magnetization recorded in experimental fires: archaeomagnetic implications. Earth and Planetary Science Letters, 312, 176-187.

Chauvin, A., Garcia, Y., Lanos Ph., Laubenheimer, F., 2000. Palaeointensity of the geomagnetic field recovered on archaeomagnetic sites from France. Physics Earth Planetary Interiors, 120, 111-136.

Conati Barbaro, C., 2013. Cooking, working and burying in Ancient Neolithic: The ovens of Portonovo (Marche, Italy) ), with contributions by Acquafredda P., Catalano P., Celant A., Di Giannantonio S., Lelli R., Muntoni I.M., Pallara M., Ruggero G. Origini, XXXV, 31-82.

Day, R., Fuller, M., Schmidt, V.A., 1977. Hysteresis properties of titanomagnetites: Grain size and composition dependence. Physics Earth and Planetary Interiors, 13, 260-267.

De Marco, E., Spatharas, V., Gómez-Paccard, M., Chauvin, A., Kondopoulou D., 2008. New archaeointensity results from archaeological sites and variation of the geomagnetic field intensity for the last 7 millennia in Greece. Phys. Chem. Earth, 33, 578-595.

De Marco, E., Tema, E., Lanos, Ph., Kondopoulou, D., 2014. An updated catalogue of Greek archaeomagnetic data for the last 4500 years and a directional secular variation curve. Stud. Geophys. Geod., 58, 121-147, doi: 10.1007/s11200-013-0910-y.

Dekkers, M. J., Böhnel, H. N., 2006. Reliable absolute palaeointensities independent of magnetic domain state. Earth and Planetary Science Letters, 248 (1-2), 508-517, doi: 10.1016/j.epsl.2006.05.040.

Dunlop, D.J., Carteer-Stiglitz, B., 2006. Day plots of mixtures of superparamagnetic, single-domain, pseudosingle-domain, and multidomain magnetites. Journal of Geophysical Research, 111, B12S09, doi: 10.1029/2006JB004499.

Egli, R. 2013. VARIFORC: An optimized protocol for calculating non-regular first-order reversal curve (FORC) diagrams. Global and Planetary Change, 110, 302-320. http://dx.doi.org/10.1016/j.gloplacha.2013.08.003.

Fabian, K., Leonhardt R., 2010. Multiple-specimen absolute paleointensity determination: an optimal protocol including pTRM normalization, domain-state correction, and alteration test. Earth Planetary Science Letters, 207, 84-94.

Fanjat G., 2012. Les fluctuations du champ magnétique terrestre : des variations séculaires récentes aux renversements. Available online at https://tel.archives-ouvertes.fr/tel-00719380.

Fanjat, G., Aidona, E., Kondopoulou, D., Camps, P., Rathossi, C., Poidras, T., 2013. Archeointensities in Greece during the Neolithic period: New insights into material selection and secular variation curve. Phys. Earth Planet. Int., 215, 29-42, doi: 10.1016/j.pepi.2012.10.011.

Fisher R.A., 1953. Dispersion on a sphere. Proceedings of Royal Society, London, pp.295.

Jelinek, V., 1981. Characterization of the magnetic fabric of rocks. Tectonophysics, 79, 63-67.

Hrouda, F. 2003. Indices for numerical characterization of the alteration processes of magnetic minerals taking place during investigation of temperature variation of magnetic susceptibility. Studia Geophysica et Geodaetica, 47, 847-861. 
Hus, J., Ech-Chakrouni, S., Jordanova, D., 2002. Origin of magnetic fabric in bricks: its implications in archaeomagnetism. Phys. Chem. Earth, 27, 1319-1331.

Kapper, L., Anesin, D., Donadini, F., Angelucci, D., Cavulli, F., Pedrotti, A., Hirt, A., 2014. Linking site formation processes to magnetic properties. Rock- and Archeomagnetic analysis of the combustion levels at Riparo Gaban, Italy. Journal of Archaeological Science, 41, 836-855.

Kirschvink J.L., 1980. The least-square line and plane and the analysis of palaeomagnetic data. Geophys. J. Astron. Soc., 62, 699-718.

Korte, M., Constable, C., Donadini, F., Holme, R., 2011. Reconstructing the Holocene geomagnetic field. Earth Planetary Science Letters, 312, 3-4, 497-505, doi: 10.1016/j.epsl.2011.10.031.

Kovacheva, M., Chauvin, A., Jordanova, N., Lanos, Ph., Karloukovski, V., 2009. Remanence anisotropy effect on the palaeointensity results obtained from various archaeological materials, excluding pottery. Earth Planets Space, 61, 711-732.

Kovacheva, M., Kostadinova-Avramova, M., Jordanova, N., Lanos, Ph., Boyadziev, Y., 2014. Extended and Revised Archaeomagnetic Database and secular variation curves from Bulgaria for the Last Eight Millennia. Physics Earth and Planetary Interiors, 236, 79-94.

Lanza, R., Zanella, E., 2003. Palaeomagnetic secular variation at Vulcano (Aeolian Islands) during the last 135 kyr. Earth Planet. Sci. Lett., 213, 321-336.

Lowrie, W., 1990. Identification of ferromagnetic minerals in a rock by coercivity and unblocking temperature properties. Geophys. Res. Lett., 17, 159-162.

Márton, P., 2009. Prehistorical archeomangetic directions from Hungary in comparison with those from South-eastern Europe. Earth Planets Space, 61, 1351-1356.

Muntoni, I.M., Ruggiero, G., 2013. Estimating the Firing temperatures of pyrotechnological processes in Neolithic site of Portonovo. Origini, XXXV, 52-56.

Nilsson, A., Holme, R., Korte, M., Suttie, N., Hill, M., 2014. Reconstructing Holocene geomagnetic field variation: new methods, models and implications. Geophysical Journal International, 198, 1, 229-248.

Pavón-Carrasco, F.J., Osete, M.L., Torta, J.M., De Santis, A., 2014. A geomagnetic field model for the Holocene based on archaeomagnetic and lava flow data. Earth Planetary Science Letters, 388, 98 - 109.

Prévot, M., 1981. Some aspects f magnetic viscosity in subaerial and submarine volcanic rocks. Geophys. J. R. Astr. Soc., 66, 169-192.

Reimer, P.J., Baillie, M.G.L.,Bard, E., Bayliss, A., Beck, J.W., Bertrand, C., Blackwell, P.G., Buck, C.E., Burr, G., Cutler, K.B., Damon, P.E., Edwards, R.L., Fairbanks, R.G., Friedrich, M., Guilderson, T.P., Hughen, K.A., Kromer, B., McCormac, F.G., Manning, S., Bronk Ramsey, C., Reimer, R.W., Remmele, S., Southon, R.J., Stuiver, M., Talamo, S., Taylor, F.W., van der Plicht, J., Weyhenmeyer, C.E., 2004. IntCal04 Terrestrial radiocarbon age calibration, 0-26 Cal Kyr BP. Radiocarbon, 46 (3), 1029-1058.

Reimer, P.J., Baillie, M.G.L., Bard, E., Bayliss, A., Beck, J.W., Blackwell, P.G., Bronk Ramsey, C., Buck, C.E., Burr, G.S., Edwards, R.L., Friedrich, M., Grootes, P.M., Guilderson, T.P., Hajdas, I., Heaton, T.J., Hogg, A.G., Hughen, K.A., Kaiser, K.F., Kromer, B., McCormac, F.G., Manning, S.W., Reimer, R.W., Richards, D.A., Southon, J.R., Talamo, S., Turney, C.S. M., van der Plicht, J., Weyhenmeyer, C.E. 2009. IntCal09 and Marine09 radiocarbon age calibration curves, 0-50,000 years cal BP. Radiocarbon, 51(4), 1111-1150.

Roberts, A. P., Pike, C. R. and Verosub, K. L., 2000. First order reversal curve diagrams: a new tool for characterizing the magnetic properties of natural samples. Journal of Geophysical Research , 105, 2846128475.

Schnepp, E., Lanos, Ph., 2005. Archaeomagnetic secular variation in Germany during the past 2500 years. Geophysical Journal International, 163, 479-490. 
Schnepp, E., Pucher, R., Reinders, J., Hambach, U., Soffel, H., Hedley, I., 2004. A German catalogue of archaeomagnetic data. Geophysical Journal International, 157, 64-78, doi: 10.1111/j.1365246X.2004.02163.x.

Spassov, S., Hus, J., 2006. Estimating baking temperatures in a Roman pottery kiln by rock magnetic properties: implications of thermochemical alteration on archaeointensity determinations. Geophysical Journal International, 167, 592-604.

Tema, E., Kondopoulou, D., 2011. Secular variation of the Earth's magnetic field in the Balkan region during the last eight millennia based on archaeomagnetic data. Geophysical Journal International, 186, 2, 603614, doi: 10.1111/j.1365-246X.2011.05088.x

Tema, E., Goguitchaichvili, A., Camps P., 2010. Archeointensity determination from Italy: new data and Earth's magnetic field strength variation over the past three millennia. Geophysical Journal International, 180, 596-608, doi: 10.1111/j.1365-246X.2009.04455.x

Tema, E., Hedley, I., Lanos, Ph., 2006. Archaeomagnetism in Italy: A compilation of data including new results and a preliminary Italian Secular Variation curve. Geophysical Journal International, 167, 1160-1171.

Tema, E., 2009. Estimate of the magnetic anisotropy effect on the archaeomagnetic inclination of ancient bricks. Physics of Earth and Planetary Interiors, 176, 213-223, doi: 10.1016/j.pepi.2009.05.007.

Tema, E., 2011. Archaeomagnetic Research in Italy: Recent achievements and future perspectives. In: The Earth's Magnetic Interior, IAGA Special Sopron Book Series, Volume 1, Chapter 15, pp. 213-233. Eds: Petrovsky, E., Herrero-Bervera, E., Harinarayana, T., Ivers, D., Springer, doi: 10.1007/978-94-007-0323$0 \_15$.

Thellier, E., Thellier, O., 1944. Recherches géomagnetiques sur les coulees volcaniques d'Auvergne. Ann. Geophys., 1, 37-52.

Zijderveld, J., 1967. AC demagnetization of rocks: analysis of results. In: Collinson, D., Creer, K., Runcorn, S. (Eds.), Methods in Paleomagnetism. Elsevier, New York, pp. 254-256. 


\section{Figures captions}

Fig. 1. a) Map of Italy with the location of the Portonovo archaeological site; b-c) General view of the excavated ovens; d) Photo of the PFO17 oven; e) General view of the PFO14, PFO16 and PFO16 ovens, sampled for archaeomagnetic analysis.

Fig. 2. a) Histograms of the viscosity index (\%) calculated for the three ovens; b) Normalized IRM acquisition curves up to $1.6 \mathrm{~T}$ for representative samples from the three ovens; c) Stepwise thermal demagnetization of three IRM components following Lowrie (1990). Symbols: dot= Soft$(0.1 \mathrm{~T})$; diamond= Medium- $(0.5 \mathrm{~T})$; square= Hard- $(1.6 \mathrm{~T})$ coercivity component.

Fig. 3. Low-field susceptibility versus temperature curves measured under air atmosphere (k-T curves) for a representative sample from oven PFO17. Susceptibility values are normalized to the maximum susceptibility. The heating curve is in red, the cooling curve is in blue.

Fig. 4. a) Day plot obtained from the hysteresis curves of representative specimens from the three ovens. The SD-MD and SD-SP mixing lines are calculations for magnetite from Dunlop and Carter-Stiglitz (2006). Numbers along curves are volume fractions of the soft component (SP or $\mathrm{MD}$ ) in mixtures with SD grains. All the data plot on the PSD range; b) Thermomagnetic profiles (M-T) obtained for the PFO17a sample after subsequent heating from room temperature up to $430{ }^{\circ} \mathrm{C}$ (left), $540{ }^{\circ} \mathrm{C}$ (middle), and $650{ }^{\circ} \mathrm{C}$ (right). All heating-cooling curves have been normalized to the initial magnetization at room temperature, before any treatment; c) Hysteresis curves obtained for the same PFO17a sample, before (black line) and after treatment at $430{ }^{\circ} \mathrm{C}$ (red), $540{ }^{\circ} \mathrm{C}$ (green) and $650^{\circ} \mathrm{C}$ (blue). The inset shows the behavior of the cycles around the origin of the graphs.

Fig. 5. FORC diagrams obtained from samples a) PFO14-1; b) PFO16-1; c) PFO17-1 and d) PFO17-3. Each FORC diagram is calculated from 150 FORCs measured with an averaging time of $0.1 \mathrm{~s}$. Note that the horizontal and vertical scales are the same for the four diagrams.

Fig. 6 a.) Stepwise thermal demagnetization results from representative samples from the PFO14 (left), PFO-16 (middle) and PFO-17 (left) ovens illustrated as Zijderveld plots. Symbols: full dots = declination; open dots = apparent inclination; b) Equal area projections of the ChRM directions at sample level for the three ovens. The big dot represents the mean value calculated for each oven according to Fisher statistics. 
Fig. 7. Multi-specimen (MSP) archaeointensity determinations for a) and b) oven PFO14 and c) and d) oven PFO16. Closed (open) symbols represent data used (rejected) in the robust regression of the responses in $Q$ parameters on the predictors in magnetic field $\mathrm{B}$. The MSP-BD and MSP-FC data and fitting lines are represented with magenta and blue lines, respectively. For MSP-DSC plots (red lines), data and fitting lines are calculated with $\alpha=0.5$. The dashed lines are the $65 \%$ confidence intervals on the best fitting lines.

Fig. 8. The new declination (top), inclination (middle) and intensity (bottom) data obtained in this study plotted together with available literature data from Italy, central Europe and Balkan Peninsula for the 6000-4000 BC period. The SV curves calculated from the pfm9k.1a, CALS10K.1b and SCHA.DIF.14k global geomagnetic field models have been also plotted for comparison. 


\section{Tables}

Table 1. Archaeomagnetic results. Columns: Sample; Natural Remanent Magnetization; Bulk susceptibility; Pams: degree of the Anisotropy of Magnetic Susceptibility; Declination ( ${ }^{\circ}$ ); Inclination $\left.{ }^{\circ}\right)$; MAD: Maximum Angular Deviation; Mean direction: $\mathrm{N}=$ number of independently oriented samples; $D_{m}=$ mean declination; $I_{m}=$ mean inclination; $\alpha_{95}=95 \%$ semi-angle of confidence; $k=$ precision parameter according to Fisher (1953).

Table 2. Archaeointensity results for ovens PFO-14, PFO-16 and PFO-17.

MSP archaeointensity values are estimated by the zero-crossing point of the Robust linear regression on the $Q$ parameters obtained with the MSP-DB protocol (Dekker and Bohnel, 2006), fraction correction (MSP-FC) or domain state correction protocols (Fabian and Leonhardt, 2010) as function of the laboratory field. R-squared is the coefficient of determination indicating how well data fit the model. RMSE is the root mean squared error for the fitting line. 

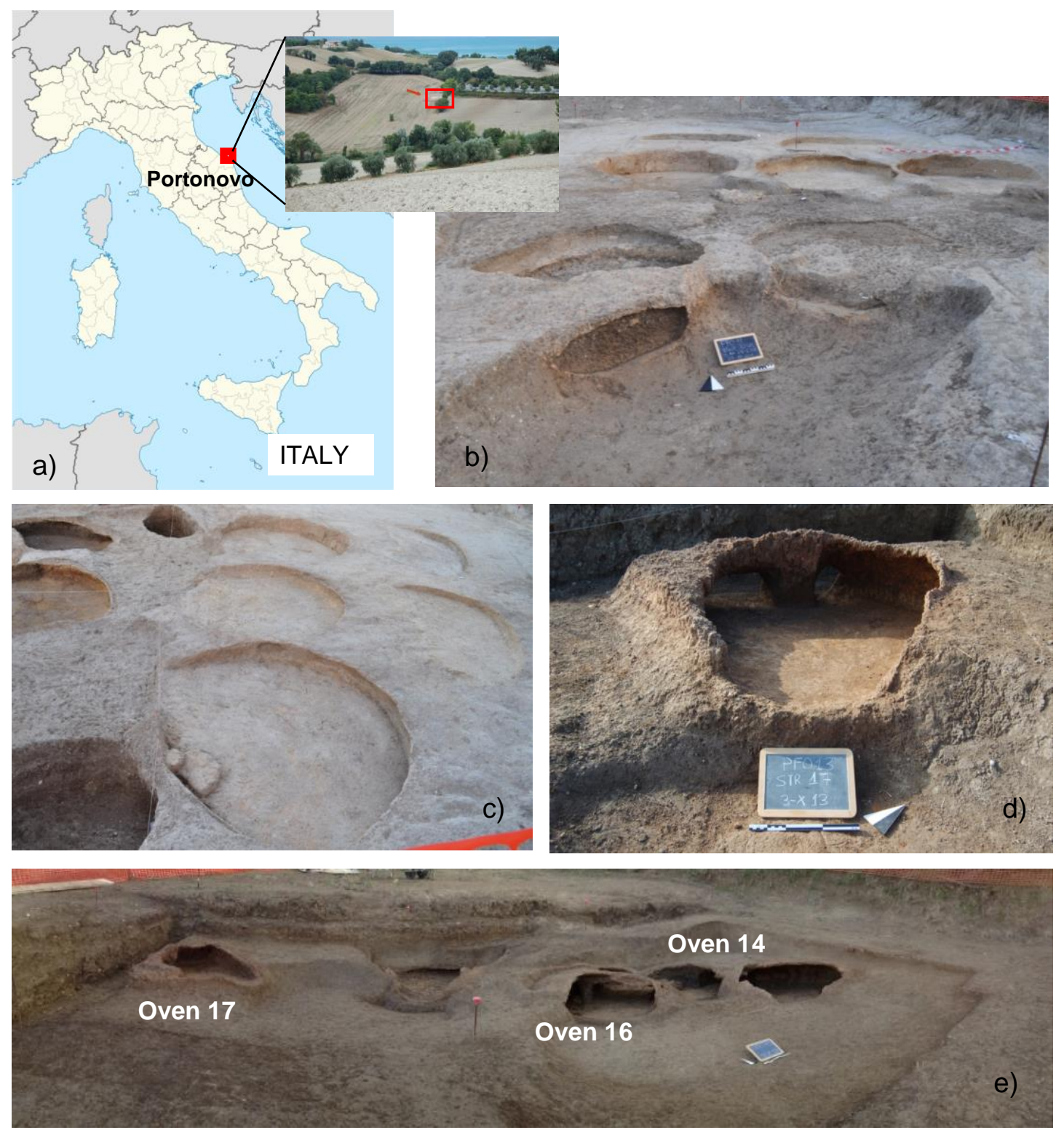

Fig. 1 
a)
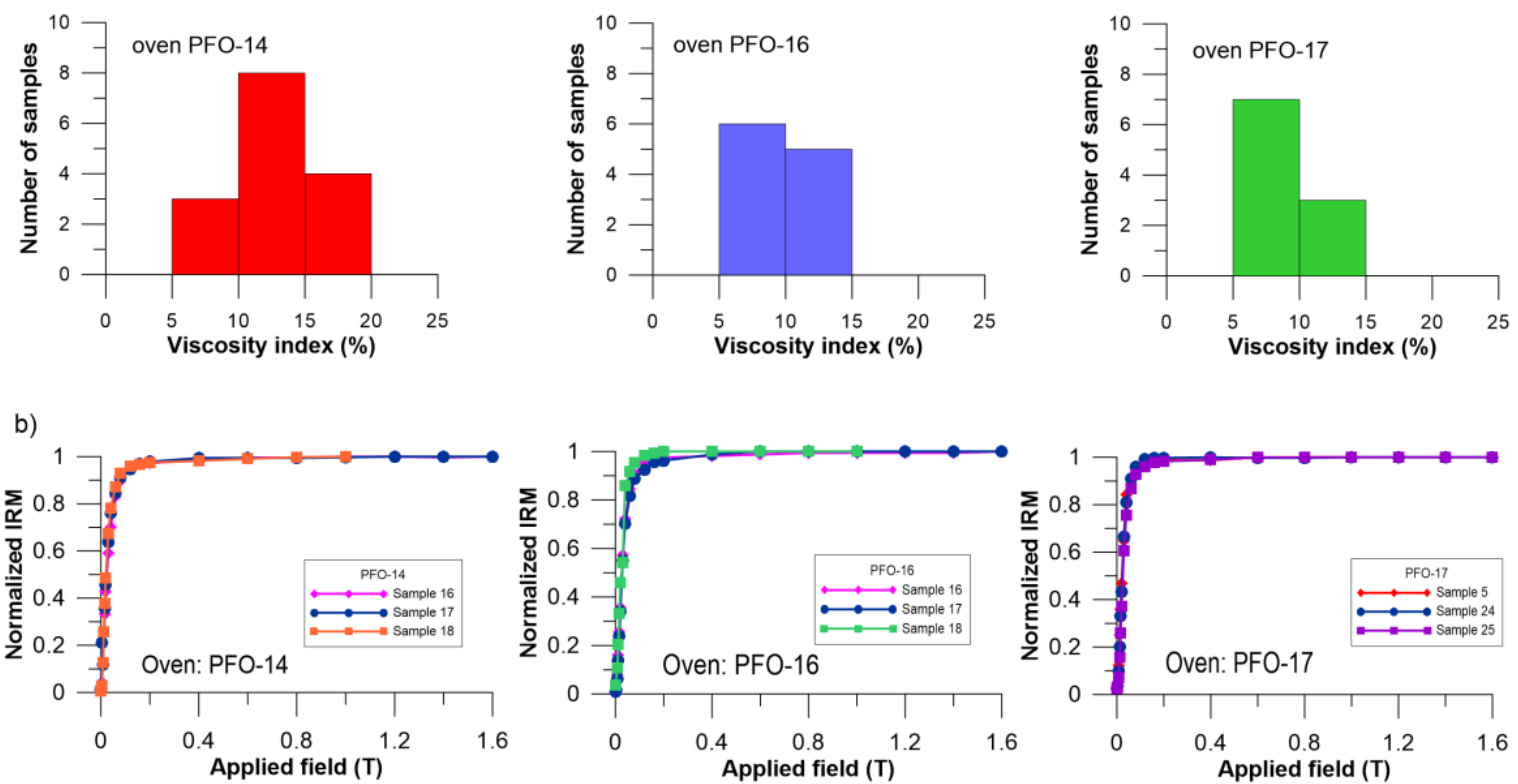

c)
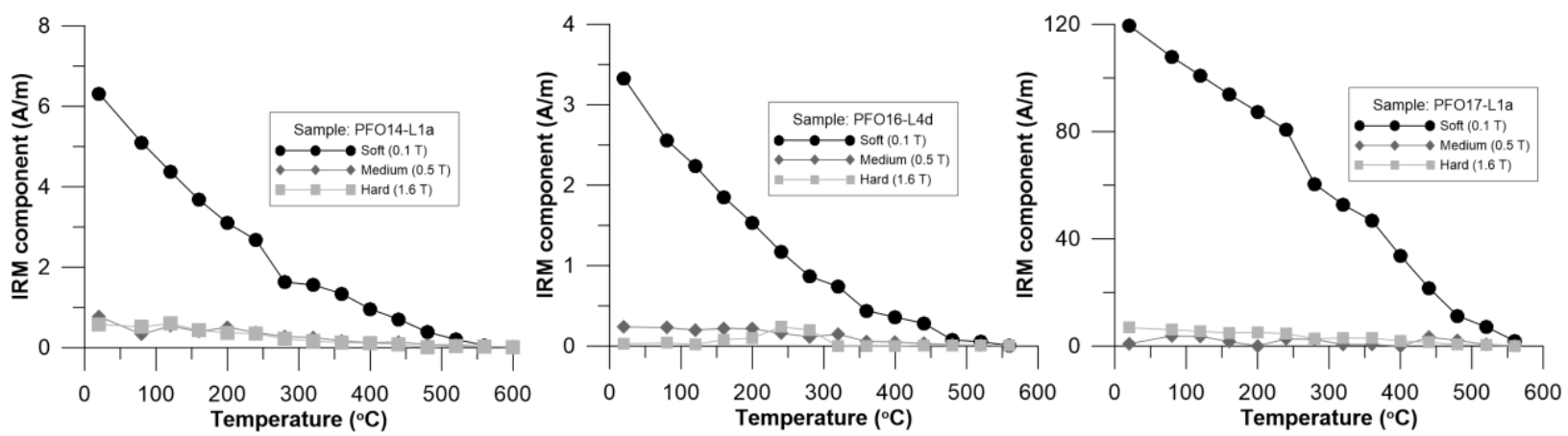

Fig. 2 


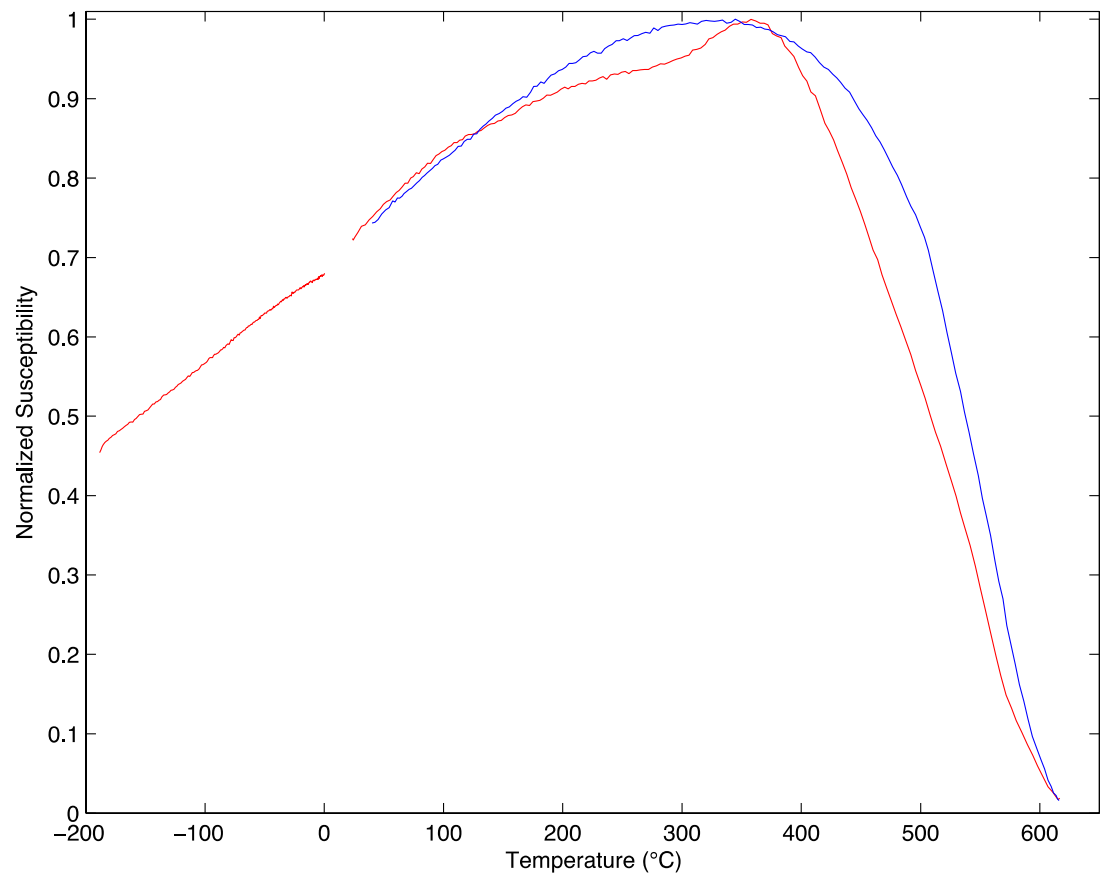

Fig. 3 


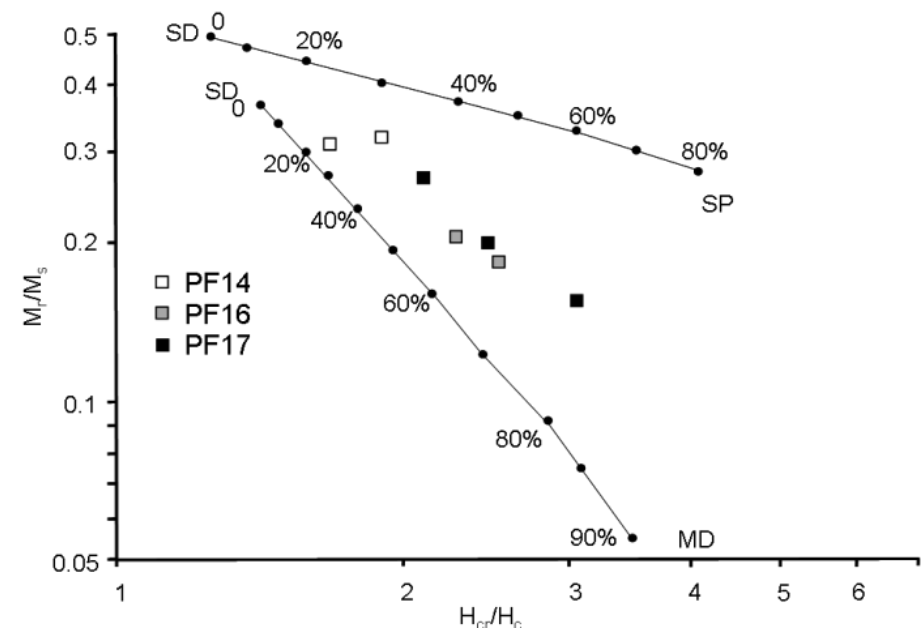

(a)
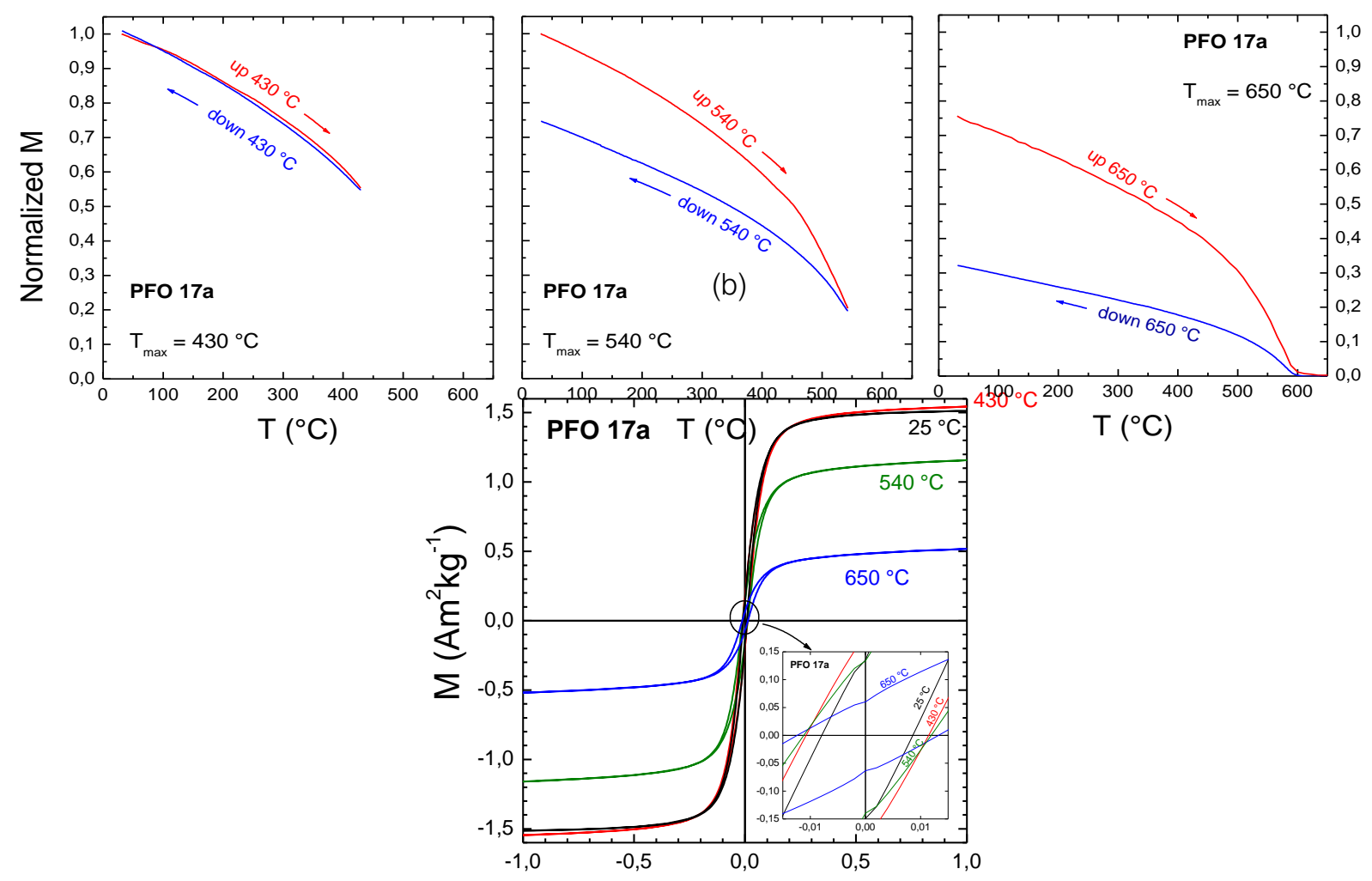

Applied Field ( $\mathrm{T}$ )

(c)

Fig. 4 
a)

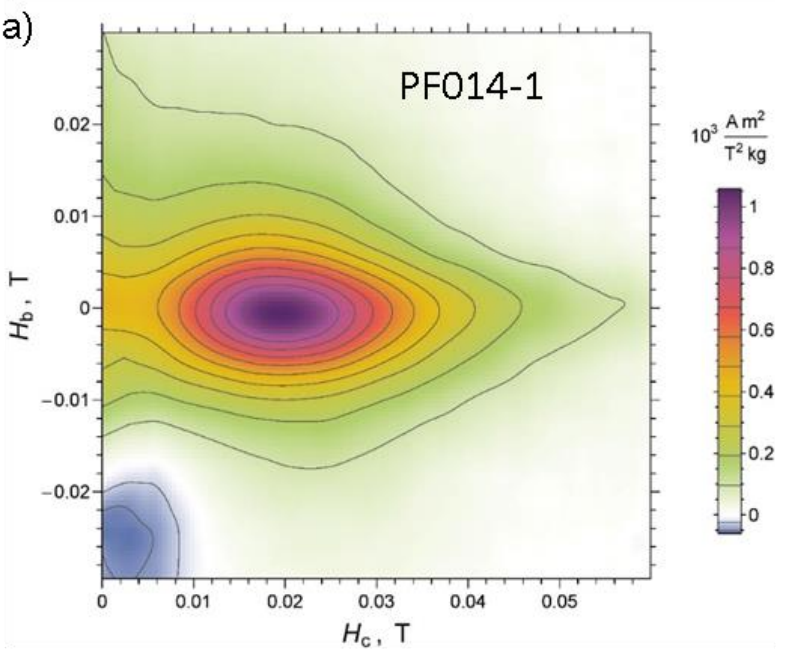

c)

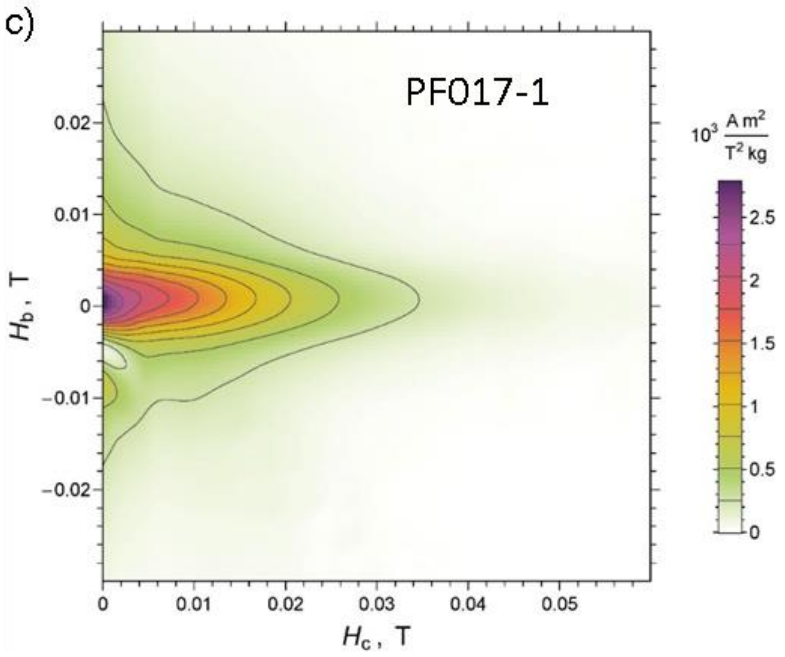

b)

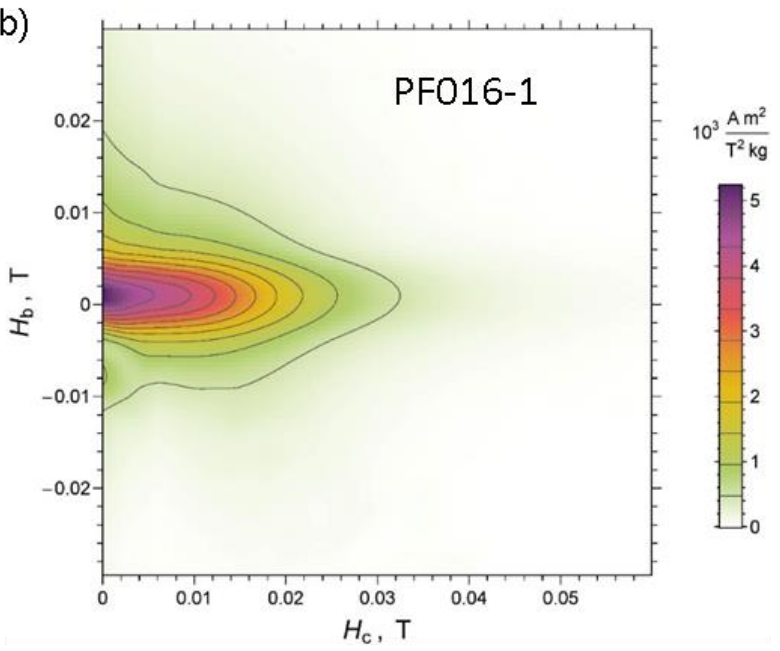

d)

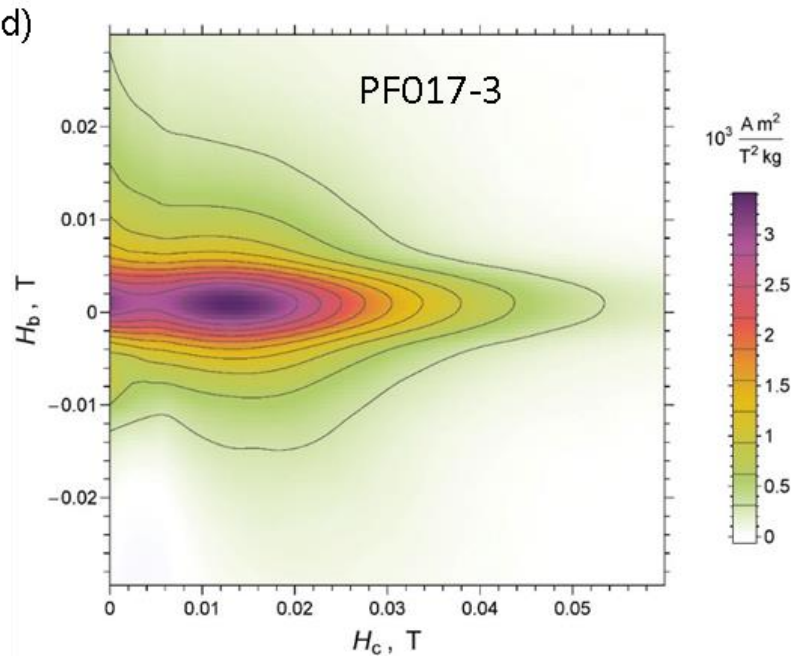

Fig. 5 


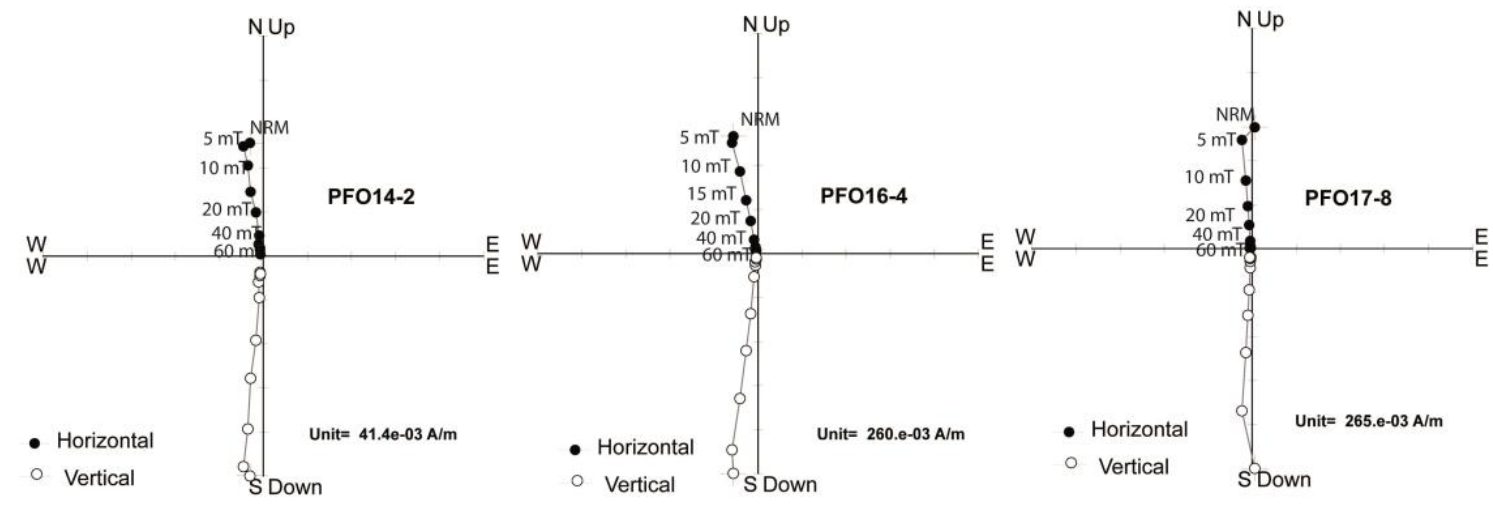

(a)

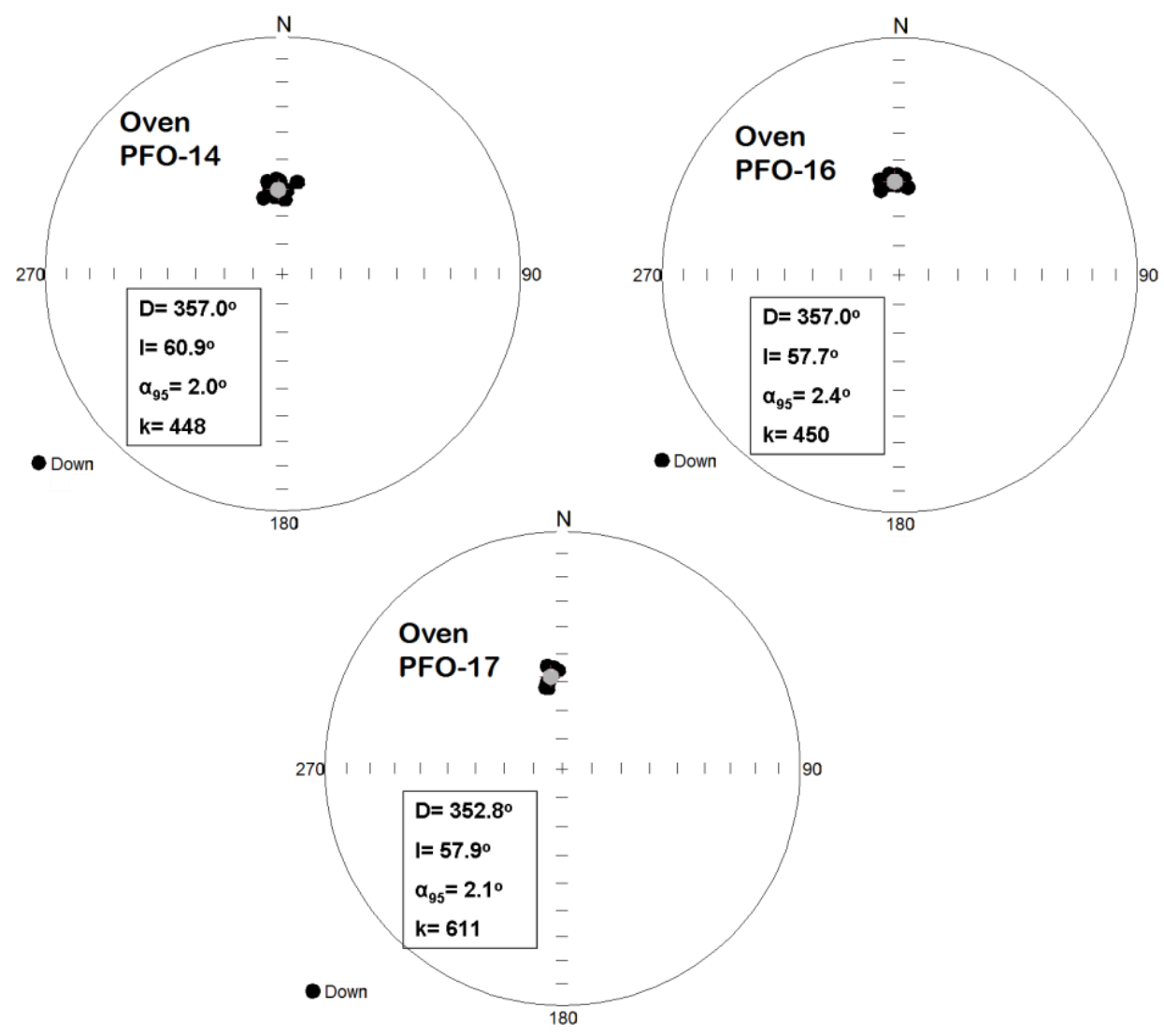

(b)

Fig. 6 

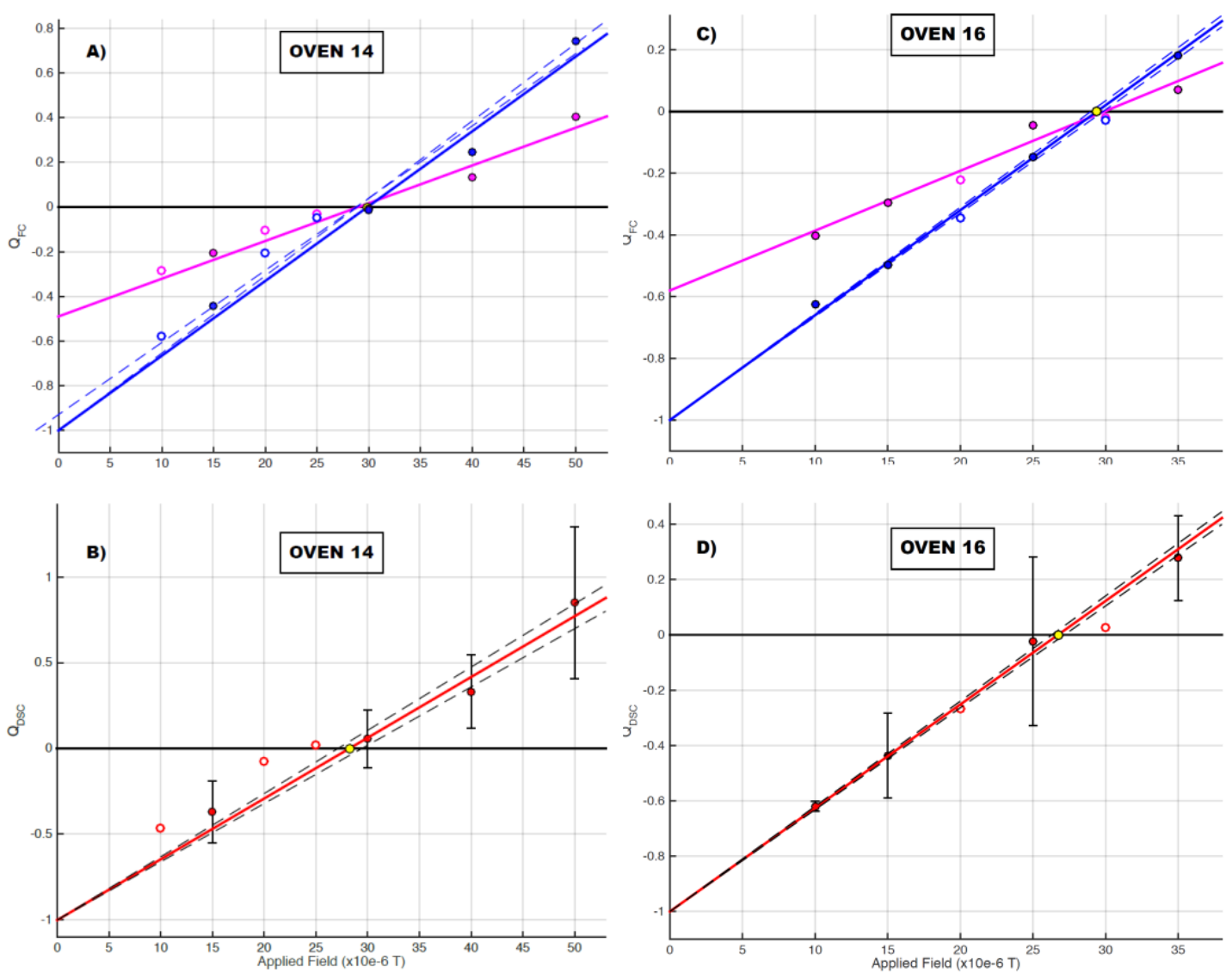

Fig. 7 
a)

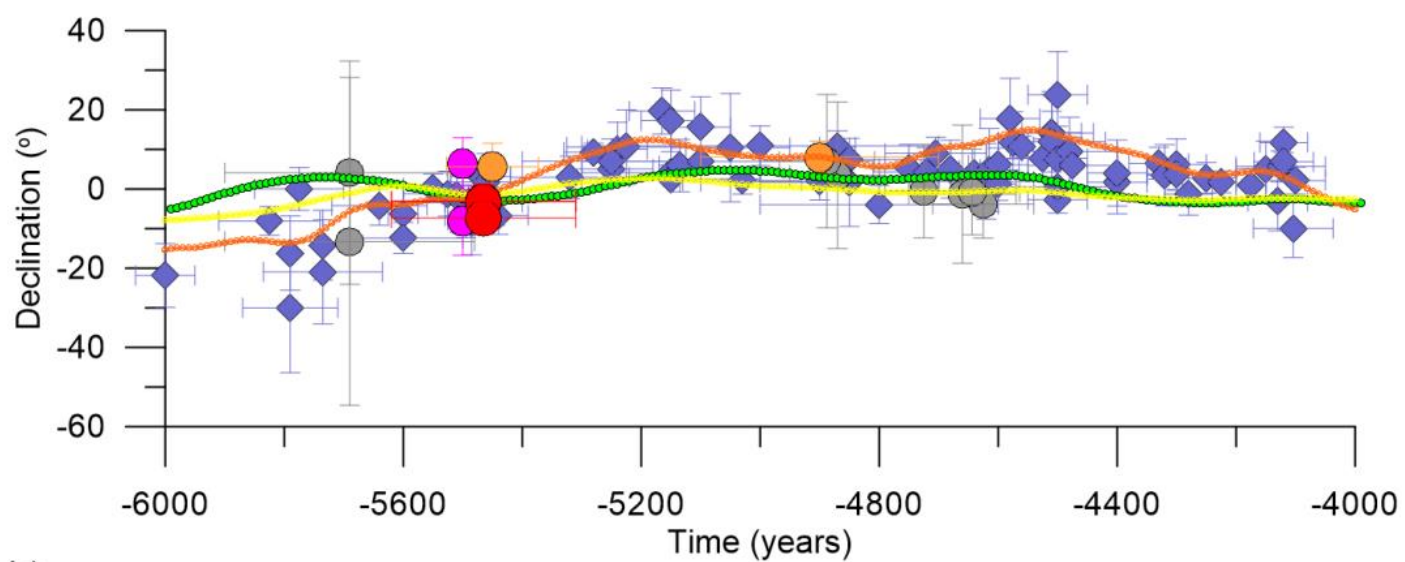

b)

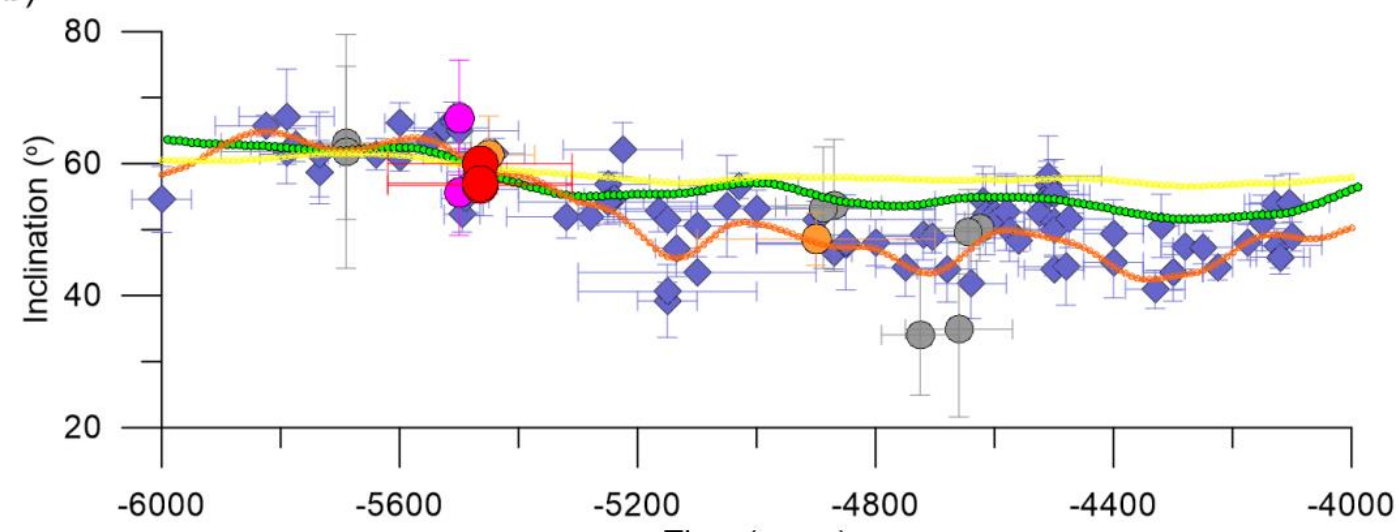

c)

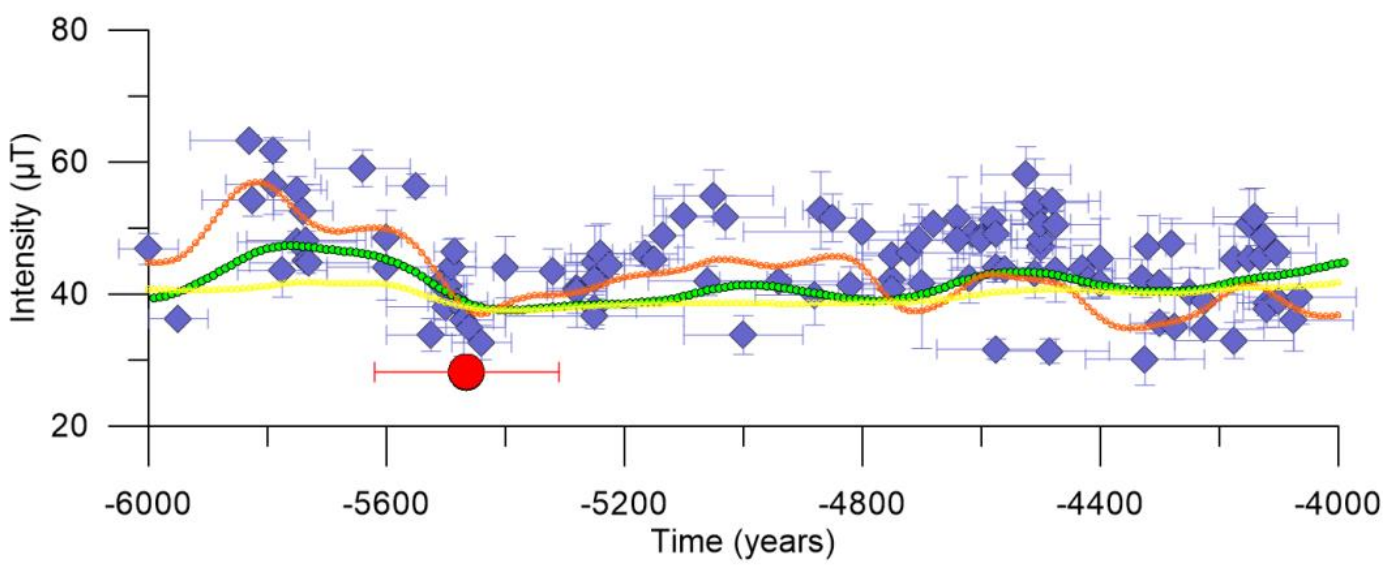

New data (This study)

Data from literature

$\begin{array}{lll}\bullet & 0 & 0 \text { Italy } \\ \bullet & \bullet & \text { Hungary } \\ \bullet & 0 & \text { Germany } \\ \bullet & \quad & \text { Balkan Peninsula }\end{array}$

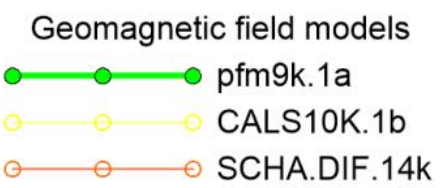

Fig. 8 



\begin{tabular}{|c|c|c|c|c|c|c|}
\hline \multicolumn{7}{|c|}{ Bulk susceptibility } \\
\hline Sample & NRM (E-03 A/m) & (E-03 SI) & Pams & $\mathrm{D}\left({ }^{\circ}\right)$ & $I\left(^{\circ}\right)$ & MAD \\
\hline \multicolumn{7}{|l|}{ Oven PFO14 } \\
\hline PFO14-1 & 526.9 & 4.253 & 1.011 & 358.5 & 57.8 & 1.3 \\
\hline PFO14-2 & 233.4 & 1.681 & 1.006 & 351.0 & 61.4 & 1.4 \\
\hline PFO14-3 & 377.0 & 2.848 & 1.009 & 9.3 & 57.7 & 0.9 \\
\hline PFO14-4 & 593.8 & 4.770 & 1.002 & 358.6 & 61.3 & 1.4 \\
\hline PFO14-5 & 351.6 & 2.548 & 1.012 & 354.9 & 63.4 & 1.4 \\
\hline PFO14-6 & 563.3 & 4.316 & 1.002 & 356.1 & 60.6 & 1.6 \\
\hline PFO14-7 & 869.9 & 5.898 & 1.011 & 355.0 & 61.5 & 1.3 \\
\hline PFO14-8 & 456.2 & 3.973 & 1.011 & 346.1 & 63.0 & 1.3 \\
\hline PFO14-9 & 509.8 & 4.173 & 1.007 & 356.4 & 57.0 & 2.4 \\
\hline PFO14-12 & 681.1 & 4.137 & 1.008 & 3.2 & 61.0 & 3.5 \\
\hline PFO14-13 & 705.7 & 4.648 & 1.007 & 2.1 & 64.3 & 1.8 \\
\hline PFO14-14 & 476.3 & 4.679 & 1.011 & 350.9 & 57.7 & 1.5 \\
\hline PFO14-15 & 567.8 & 4.368 & 1.006 & 357.9 & 63.4 & 1.6 \\
\hline \multicolumn{7}{|c|}{ Mean direction: } \\
\hline$N=13$ & $D_{m}=357.0^{\circ}$ & $I_{m}=60.9^{\circ}$ & $\alpha_{95}=2.0^{\circ}$ & $k=448$ & & \\
\hline \multicolumn{7}{|l|}{ Oven PFO16 } \\
\hline PFO16-4 & 1479 & 7.090 & 1.007 & 347.7 & 60.1 & 0.7 \\
\hline PFO16-5 & 1438 & 6.271 & 1.007 & 2.8 & 56.4 & 0.9 \\
\hline
\end{tabular}




\begin{tabular}{|c|c|c|c|c|c|c|}
\hline PFO16-6 & 751.6 & 5.539 & 1.003 & 5.6 & 59.5 & 1.2 \\
\hline PFO16-7 & 1212 & 7.036 & 1.004 & 354.3 & 54.8 & 0.9 \\
\hline PFO16-8 & 899.2 & 5.725 & 1.013 & 354.8 & 58.7 & 1.3 \\
\hline PFO16-9 & 1022 & 5.516 & 1.007 & 1.7 & 57.7 & 1.4 \\
\hline PFO16-11 & 1399 & 7.888 & 1.007 & 358.9 & 59.0 & 1.1 \\
\hline PFO16-12 & 1223 & 7.030 & 1.010 & 358.8 & 55.2 & 1.5 \\
\hline PFO16-13 & 1110 & 6.848 & 1.008 & 348.4 & 56.3 & 1.3 \\
\hline \multicolumn{7}{|c|}{ Mean direction: } \\
\hline$N=9$ & $D_{m}=357.0^{\circ}$ & $\mathrm{I}_{\mathrm{m}}=57.7^{\circ}$ & $\alpha_{95}=2.4^{\circ}$ & $k=450$ & & \\
\hline \multicolumn{7}{|c|}{ Oven PFO17 } \\
\hline PFO17-7 & 916.78 & 9.441 & 1.003 & 351.2 & 59.5 & 1.9 \\
\hline PFO17-8 & 1514 & 10.94 & 1.002 & 355.4 & 55.1 & 1.4 \\
\hline PFO17-9 & 2043 & 12.39 & 1.023 & 357.7 & 56.0 & 1.0 \\
\hline PFO17-11 & 2143 & 10.65 & 1.004 & 353.5 & 57.7 & 0.9 \\
\hline PFO17-12 & 1753 & 10.13 & 1.002 & 356.1 & 56.0 & 1.3 \\
\hline PFO17-13 & 2100 & 13.14 & 1.004 & 349.8 & 61.8 & 0.9 \\
\hline PFO17-14 & 2089 & 14.96 & 1.003 & 348.3 & 61.4 & 1.4 \\
\hline PFO17-15 & 1985 & 11.94 & 1.005 & 350.2 & 59.6 & 0.9 \\
\hline PFO17-16 & 2287 & 12.57 & 1.003 & 351.8 & 54.0 & 2.5 \\
\hline \multicolumn{7}{|c|}{ Mean direction: } \\
\hline$N=9$ & $D_{m}=352.8^{\circ}$ & $I_{m}=57.9^{\circ}$ & $\alpha_{95}=2.1^{\circ}$ & $k=611$ & & \\
\hline
\end{tabular}




\begin{tabular}{|c|c|c|c|c|c|}
\hline Method & $\mathrm{PI}(\mu \mathrm{T})$ & $65 \%$ conf. & $n / N$ & R-squared & RMSE \\
\hline \multicolumn{6}{|l|}{ Oven 14} \\
\hline MSP-DB & 29.0 & {$[26.6-31.1]$} & $4 / 7$ & 0.9665 & 0.0575 \\
\hline MSP-FC & 29.9 & [28.9 - 30.9] & $4 / 7$ & 0.9766 & 0.0760 \\
\hline MSP-DSC $(\alpha=0.2)$ & 29.4 & {$[27.1-29.4]$} & $4 / 7$ & 0.9701 & 0.1845 \\
\hline MSP-DSC $(\alpha=0.8)$ & 27.2 & {$[28.3-30.6]$} & $4 / 7$ & 0.9546 & 0.1866 \\
\hline MSP-DSC $(\alpha=0.5)$ & 28.2 & {$[27.1-29.4]$} & $4 / 7$ & 0.9630 & 0.1842 \\
\hline \multicolumn{6}{|l|}{ Oven 16} \\
\hline MSP-DB & 29.9 & [28.3 - 31.9] & $4 / 7$ & 0.9746 & 0.0425 \\
\hline MSP-FC & 29.4 & [29.0 - 29.8] & $4 / 7$ & 0.9968 & 0.0205 \\
\hline MSP-DSC ( $\alpha=0.2)$ & 27.8 & {$[27.2-28.4]$} & $4 / 7$ & 0.9942 & 0.1076 \\
\hline MSP-DSC $(\alpha=0.8)$ & 25.7 & [25.2 - 26.2] & $4 / 7$ & 0.9957 & 0.0860 \\
\hline MSP-DSC $(\alpha=0.5)$ & 26.7 & {$[26.3-27.2]$} & $4 / 7$ & 0.9972 & 0.0711 \\
\hline \multicolumn{6}{|l|}{ Oven 17} \\
\hline MSP & n.d. & n.d & $3 / 7$ & n.d & n.d \\
\hline
\end{tabular}


Table 2 